\title{
Endoscopic Thulium Laser Ablation of Upper Tract Urothelial Carcinoma: a Retrospective Study with Subgroup Analyses
}

\section{Yu Che Hsieh}

Chi Mei Medical Center

Steven K. Huang

Chi Mei Medical Center

Chia-Cheng Su

Chi Mei Medical Center

Jhih-Cheng Wang

Chi Mei Medical Center

\section{Kun-Hung Shen}

Chi Mei Medical Center

I-Jung Feng

Chi Mei Medical Center

Allen W. Chiu

Mackay Memorial Hospital

Chien-Liang Liu ( $\nabla$ 5723221play@gmail.com )

https://orcid.org/0000-0001-8127-588X

\section{Research article}

Keywords: Carcinoma, Transitional Cell, Conservative treatment, Endoscopy, Laser therapy, Thulium

Posted Date: January 6th, 2020

DOI: https://doi.org/10.21203/rs.2.20091/v1

License: (1) (1) This work is licensed under a Creative Commons Attribution 4.0 International License. Read Full License 


\section{Abstract}

Introduction

The gold standard treatment for upper tract urothelial carcinomas (UTUC) is radical nephroureterectomy with bladder-cuff excision. However, the role of combination of ureterorenoscopy and laser ablation has recently become more essential. This study aimed to investigate the efficacy of Thulium laser ablation of UTUC and estimate clinical outcomes with subgroup analyses.

\section{Methods}

After obtaining informed consent, we retrospectively reviewed all patients who had undergone endoscopic Thulium laser ablation of UTUC as their primary treatment from Jun 2012, to Nov 2018. Sixtyeight patient were enrolled, and thirty-four patients were analyzed after selection by exclusion criteria. Comparisons with bivariate analyses between patients with and without recurrence were examined. Multivariable cox regression model were further applied. Further, Kaplan-Meier survival estimate were presented with comparison of the survival curves, we also combined two of three tumor characteristics (stage, size, and grade of tumor) for subgroup analyses.

Results

Fifteen patients (44\%) had local tumor recurrence. Seven patients $(21 \%)$ had recurrence at the urinary bladder. Two patients $(6 \%)$ had lymph node or distal metastasis. A total of 4 patients $(12 \%)$ had cancerspecific death. In bivariate analyses, statistical significance is noted for age, tumor grade and tumor size with p-values of $0.018,0.047$ and 0.014 , respectively. In the multivariable analysis, statistical significance is noted for age and tumor size with p-values of 0.017 , and 0.042 , respectively. In Kaplan-Meier estimate for subgroup analysis, statistical significance is only noted in the tumor size + tumor grade group but almost achieved in the tumor size + biopsy stage group with p-value of 0.0275 and 0.0518 , respectively.

\section{Conclusion}

In our experience, tumor size and tumor grade are influential recurrence factors. However, biopsy stage does not achieve statistical significance in both the recurrence analysis and survival estimate. In the subgroup analyses, tumor size is a more influential factor than tumor grade in the prognosis of local recurrence.

\section{Introduction}

Upper tract urothelial carcinomas (UTUC) are rare malignancies and account for $5 \%-10 \%$ of all urothelial carcinomas (UC) [1]. However, an increased prevalence was noted at high-arsenic exposure areas, such as southwestern and northeastern Taiwan, where residents are at high risk of lung cancer, bladder cancer, and black foot disease. Residents have consumed arsenic-contaminated water from artesian wells for more than 40 years, and the odds ratio of bladder cancer is 4.10 [2]. This group of patients has unique 
characteristics, (1) arsenic exposure will disproportionally induce a high incidence rate of UTUC (20\%-25\%) among all UCs [3, 4]. (2) Ureteral UCs are twice as common as renal pelvic UCs. (3) The maleto-female ratio among this group of patient is $1: 2$, in contrast to the male predominance seen in other regions of the world [5].

The incidence of UTUC in Western countries is 2.0/100,000 persons and accounts for only $5 \%-10 \%$ of UCs. Renal pelvic UCs are approximately twice as common as ureteral UCs [6]. However, the incidence of UTUC in Taiwan is 5.56/100,000 persons in males and 7.37/100,000 persons in females [7]. Due to its high prevalence in southwestern Taiwan, we thus managed more patients with UTUC than other regions did. Compared with urinary bladder UC, UTUC tends to have a worse prognosis as a multifocal disease with a high recurrence rate; the 5 -year urinary bladder recurrence rate is $28 \%$, and the 5 -year mortality rate is $23 \%$ [8].

Conventionally, the gold standard treatment for UTUC is radical nephroureterectomy (RNU) with bladdercuff excision. Because of the continuous progress of the image and endoscopic armamentarium, the role of kidney-sparing surgery (KSS) has recently become more essential. According to the latest European Association of Urology (EAU) guidelines [6], well-selected patients with UTUC are suitable candidates for KSS. In low-risk patients (unifocal disease, tumor size $<2 \mathrm{~cm}$, low-grade cytology, low-grade URS biopsy, and no invasive aspect on computed tomography urography [CTU]), similar cancer-specific survival (CSS) is noted between the KSS and RNU groups [9].

Due to the advanced development of flexible ureterorenoscopy (URS), we can check the collecting system in detail. URS treatment for UTUC by electrode has shifted to laser ablation with Holmium:YAG laser or Thulium laser [10,11]. Laser ablation has been investigated since the last decade, compared with traditional electrode resection; the advantage is that it provides a continuous wave for sharply defined resection and fulguration of the tumor bed with excellent hemostasis. Thulium laser ablation showed superior recurrence-free survival, reduced bleeding, and less mucosal perforation compared with Holmium laser ablation [12].

This study aimed to investigate the efficacy of laser ablation of UTUC and estimate clinical outcomes with subgroup analyses.

\section{Materials And Methods}

After obtaining informed consent, we retrospectively reviewed all patients who had undergone endoscopic Thulium laser ablation of UTUC as their primary treatment from Jun 2012, to Nov 2018. All UTUCs were diagnosed by URS biopsy. The indications for laser ablation of UTUC were (1) a low-risk tumor as defined by EAU guidelines [6], (2) existence in a solitary kidney, (3) chronic kidney disease of stage $\geq 3$, (4) bilateral UTUC, and (5) advanced medical comorbidities enough to be life-limiting or cause additional risk with RNU. 
Sixty-eight patients received laser ablation of UTUC, whereas 34 patients were excluded because of (1) the follow-up duration was shorter than 6 months, (2) a history of urinary bladder UC, and (3) the concomitant diagnosis of UTUC and bladder UC at the first visit. All patients received a diagnostic evaluation, including intravenous pyelography, urine cytology, retrograde pyelography, CTU /magnetic resonance imaging (MRI), and cystoscopy or URS. For most patients, a biopsy of the tumor and urine cytology was obtained initially. After a discussion with the patient, Thulium laser ablation was performed. Flexible URS was performed if the tumor was located at the renal pelvis. The Thulium laser system is the "Quanta" Cyber Tm 200 Thulium Laser System. For renal pelvic UC, we used flexible URS with optical fiber $200 \mu \mathrm{m}$, and the power of Laser was 10-15 watts. For ureteral UC, we used rigid URS with optical fiber $365 \mu \mathrm{m}$, and the power of Laser was 15-30 watts.

Three months after the first endoscopic Thulium laser ablation, 2nd -look URS was performed. A routine biopsy of the previous ablation site was performed to determine the recurrence status and could be followed by a second Thulium laser ablation of the previous tumor site. The second procedure of laser ablation might not be performed if no suspicious lesion was found. However, if the biopsy of 2nd -look URS showed recurrence, then the third endoscopic Thulium laser ablation would be scheduled. Patients were followed by a stringent surveillance protocol, including cystoscopy, retrograde pyelography, and URS every 3 months until they were tumor-free. Once the patient was free of tumor, a URS evaluation was scheduled every 6 months for 5 years and then yearly thereafter. A CTU or MRI with contrast was ordered if the baseline retrograde pyelography suggested local recurrence of UTUC.

\section{Statistical Analysis}

Continuous and categorical data in the clinical characteristics of patients and tumors were separately presented by count with percentage and median with range (Table 1 \& Table 2). Comparisons with bivariate analysis between patients with and without recurrence were examined by Wilcoxon rank sum test for continuous data and by Chi-square test or Fisher's exact test for categorical data (Table 3). Multivariable cox regression model, which is adjusted by age, biopsy stage, tumor grade and tumor size, was further applied for identifying the association between clinical characteristics and risk factors of recurrence (Table 4). Survival estimates were calculated by Kaplan-Meier method (Table 5). Further, Kaplan-Meier survival plot were presented for each group and the comparison of survival curves were tested by log rank test. We also combined two of three tumor characteristics (stage, size, and grade of tumor) for subgroup analyses. In this study, the difference were considered significant if the p-value was smaller than 0.05 . 
Table 1

\begin{tabular}{|ll|}
\multicolumn{2}{|c|}{ Patient Characteristics (N = 34) } \\
\hline \multicolumn{2}{|c|}{ No. (\%) } \\
\hline Age, median (range) & $71(36-89)$ \\
\hline Gender & $10(29 \%)$ \\
\hline Male & $24(71 \%)$ \\
\hline Female & \\
Laterality & $16(47 \%)$ \\
\hline Left & $13(38 \%)$ \\
\hline Right & $5(15 \%)$ \\
\hline Bilateral & \\
\hline Indication & $7(20 \%)$ \\
\hline Soliditary kidney & $8(24 \%)$ \\
\hline CKD (stage 3-5) & $8(24 \%)$ \\
\hline Small, low grade tumor & $5(15 \%)$ \\
\hline Bilateral disease & $6(17 \%)$ \\
\hline Advanced medical comorbidity & $25.0(6-77)$ \\
\hline Mean follow up months (range) & \\
\hline
\end{tabular}


Table 2

Tumor Characteristics $(\mathrm{N}=$ 34)

\begin{tabular}{|ll|}
\hline & No. (\%) \\
\hline Tumor site & \\
\hline Ureter & $21(62 \%)$ \\
\hline Renal pelvis & $13(38 \%)$ \\
\hline Tumor Grade & \\
\hline Low & $9(26 \%)$ \\
\hline High & $25(74 \%)$ \\
\hline Biopsy Stage & \\
\hline Ta & $9(26 \%)$ \\
\hline $\begin{array}{l}\text { Tis } \\
\text { T1 }\end{array}$ & $2(6 \%)$ \\
\hline $\begin{array}{l}\text { Tumor size } \\
<2 \\
>2 \\
\text { cm }\end{array}$ & $23(68 \%)$ \\
\hline
\end{tabular}


Table 3

Demographic and clinical characteristics of patients with and without recurrence (Bivariate analysis)

\begin{tabular}{|c|c|c|c|}
\hline & Recurrence & & p-value* \\
\hline & Yes, $n=15$ & No (free), $n=19$ & \\
\hline Age (years), median (Q1, Q3) & $77(70,86)$ & $70(61,74)$ & 0.018 \\
\hline Gender & & & 0.068 \\
\hline Male & $7(70.00 \%)$ & $3(30.00 \%)$ & \\
\hline Female & $8(33.33 \%)$ & $16(66.67 \%)$ & \\
\hline Laterality & & & 0.331 \\
\hline Left & $9(56.25 \%)$ & $7(43.75 \%)$ & \\
\hline Right & $5(38.46 \%)$ & $8(61.54 \%)$ & \\
\hline Bilateral & $1(20.00 \%)$ & $4(80.00 \%)$ & \\
\hline Tumor site & & & 0.728 \\
\hline Ureter & $10(47.62 \%)$ & $11(52.38 \%)$ & \\
\hline Renal pelvic & $5(38.46 \%)$ & $8(61.54 \%)$ & \\
\hline Tumor grade & & & 0.047 \\
\hline Low & $1(11.11 \%)$ & $8(88.89 \%)$ & \\
\hline High & $14(56.00 \%)$ & $11(44.00 \%)$ & \\
\hline Biopsy stage & & & 0.442 \\
\hline $\mathrm{Ta}$ & $3(33.33)$ & $6(66.67)$ & \\
\hline Tis & $0(0.00)$ & $2(100.00)$ & \\
\hline T1 & $12(52.17)$ & $11(47.83)$ & \\
\hline Tumor size & & & 0.014 \\
\hline$<2 \mathrm{~cm}$ & $5(25.00)$ & $15(75.00)$ & \\
\hline$>2 \mathrm{~cm}$ & $10(71.43)$ & $4(28.57)$ & \\
\hline Intra-ureteral chemotherapy & & & 0.634 \\
\hline Yes & $3(60.00)$ & $2(40.00)$ & \\
\hline No & $12(41.38)$ & $17(58.62)$ & \\
\hline
\end{tabular}


Table 4

Analyses of risk factors of recurrence by multivariable cox regression model

\begin{tabular}{|c|c|c|c|c|}
\hline & Crude HR & p-value & Adjusted HR\# & p-value \\
\hline Age & $\begin{array}{l}1.104 \\
(1.031,1.182)\end{array}$ & 0.0047 & $\begin{array}{l}1.085 \\
(1.014,1.160)\end{array}$ & 0.017 \\
\hline \multicolumn{5}{|l|}{ Gender } \\
\hline Female & ref & - & ref & - \\
\hline Male & $\begin{array}{l}2.662 \\
(0.962,7.368)\end{array}$ & 0.059 & $\begin{array}{l}2.090 \\
(0.704,6.201)\end{array}$ & 0.184 \\
\hline \multicolumn{5}{|l|}{ Laterality } \\
\hline Left & ref & - & ref & - \\
\hline Right & $\begin{array}{l}0.680 \\
(0.227,2.034)\end{array}$ & 0.490 & $\begin{array}{l}1.410 \\
(0.407,4.878)\end{array}$ & 0.588 \\
\hline Bilateral & $\begin{array}{l}0.263 \\
(0.033,2.077)\end{array}$ & 0.205 & $\begin{array}{l}1.270 \\
(0.109,14.763)\end{array}$ & 0.849 \\
\hline \multicolumn{5}{|l|}{ Tumor site } \\
\hline Ureter & ref & - & ref & - \\
\hline Renal pelvic & $\begin{array}{l}0.981 \\
(0.332,2.898)\end{array}$ & 0.973 & $\begin{array}{l}0.712 \\
(0.177,2.869)\end{array}$ & 0.633 \\
\hline \multicolumn{5}{|l|}{ Tumor grade } \\
\hline Low & ref & - & ref & - \\
\hline High & $\begin{array}{l}5.827 \\
(0.765,44.366)\end{array}$ & 0.089 & $\begin{array}{l}3.120 \\
(0.386,25.186)\end{array}$ & 0.286 \\
\hline \multicolumn{5}{|l|}{ Biopsy stage } \\
\hline Ta & $\begin{array}{l}0.575 \\
(0.162,2.038)\end{array}$ & 0.391 & $\begin{array}{l}0.696 \\
(0.194,2.503)\end{array}$ & 0.579 \\
\hline Tis & $-(-,-)$ & - & $-(-,-)$ & - \\
\hline T1 & ref & - & ref & - \\
\hline \multicolumn{5}{|l|}{ Tumor size } \\
\hline$<2 \mathrm{~cm}$ & ref & - & ref & - \\
\hline
\end{tabular}

$\mathrm{HR}=$ Hazard ratio, ref $=$ reference

\# Age, biopsy stage, tumor grade and tumor size were adjusted in the multivariable cox regression model 


\begin{tabular}{|lllll|}
\hline & Crude HR & p-value & Adjusted HR & p-value \\
\hline$>2 \mathrm{~cm}$ & $\begin{array}{l}3.880 \\
(1.317,11.434)\end{array}$ & 0.014 & $\begin{array}{l}3.225 \\
(1.041,9.988)\end{array}$ & 0.042 \\
\hline Intra-ureteral chemotherapy & & & & \\
\hline No & ref & - & ref & - \\
\hline Yes & $\begin{array}{l}1.124 \\
(0.314,4.020)\end{array}$ & 0.857 & 1.061 & 0.932 \\
\hline HR = Hazard ratio, ref = reference & & & & \\
\hline $\begin{array}{l}\text { \# Age, biopsy stage, tumor grade and tumor size were adjusted in the multivariable cox regression } \\
\text { model }\end{array}$ & & & \\
\hline
\end{tabular}

Table 5

Survival rate analyses by Kaplan-Meir's estimate

\begin{tabular}{|lllll|}
\hline $\begin{array}{l}\text { mean } \\
(95 \% \\
\text { Cl) }\end{array}$ & $\begin{array}{l}\text { 2 years local } \\
\text { recurrence-free } \\
\text { survival rate }\end{array}$ & $\begin{array}{l}\text { 2 years bladder } \\
\text { recurrence-free } \\
\text { survival rate }\end{array}$ & $\begin{array}{l}\text { 2 years } \\
\text { metastatic-free } \\
\text { survival rate }\end{array}$ & $\begin{array}{l}\text { 2 years cancer- } \\
\text { specific survival } \\
\text { rate }\end{array}$ \\
\hline $\begin{array}{l}\text { Tumor } \\
\text { site }\end{array}$ & & & & \\
\hline Ureter & $0.49(0.26,0.69)$ & $0.70(0.40,0.87)$ & $0.86(0.54,0.97)$ & $0.87(0.56,0.96)$ \\
\hline $\begin{array}{l}\text { Renal } \\
\text { pelvic }\end{array}$ & $0.60(0.29,0.81)$ & $0.84(0.49,0.96)$ & 1.00 & 1.00 \\
\hline $\begin{array}{l}\text { Tumor } \\
\text { grade }\end{array}$ & & & & 1.00 \\
\hline $\begin{array}{l}\text { Low } \\
\text { High }\end{array}$ & $0.89(0.43,0.98)$ & 1.00 & 1.00 & $0.87(0.56,0.96)$ \\
\hline $\begin{array}{l}\text { Biopsy } \\
\text { stage }\end{array}$ & $0.39(0.19,0.58)$ & $0.63(0.36,0.82)$ & $0.86(0.51,0.97)$ & \\
\hline Ta & $0.63(0.23,0.87)$ & $0.88(0.41,0.98)$ & 1.00 & 1.00 \\
\hline Tis & 1.00 & 1.00 & 1.00 & 1.00 \\
\hline T1 & $0.41(0.19,0.62)$ & $0.64(0.33,0.83)$ & $0.85(0.47,0.96)$ & $0.85(0.53,0.96)$ \\
\hline $\begin{array}{l}\text { Tumor } \\
\text { size }\end{array}$ & $0.71(0.43,0.87)$ & $0.77(0.47,0.90)$ & $0.86(0.51,0.96)$ & $1.00(-,-)$ \\
\hline$<2 \mathrm{~cm}$ & $0.63(0.17,0.89)$ & $1.00(-,-)$ & $0.69(0.23,0.91)$ \\
\hline$>2 \mathrm{~cm}$ & $0.23(0.04,0.49)$ & & & \\
\hline
\end{tabular}




\section{Results}

Thirty-four patients fulfilled the inclusion and exclusion criteria. Patients' ages ranged from 36 to 89 years old, with a median of 71 years old. Female predominance ( 24 of $34,71 \%$ ) was noted (Table 1$)$. Fifteen patients (44\%) had local tumor recurrence during follow-up. Seven patients $(21 \%)$ had recurrence at the urinary bladder. Two patients (6\%) had lymph node or distal metastasis; one patient had lung metastasis and eventually died by the 9th -month follow-up; one patient had para-aortic lymph node metastasis and bone metastasis, eventually died by the 28th -month follow-up. A total of 4 patients (12\%) had cancerspecific death during follow-up, another 2 patients died due to obstructive uropathy with urosepsis. A 69year-old patient received laser ablation once; then treatment was shifted to RNU because of persistent hematuria. The final pathology showed T2N0. Five patients (15\%) had ureteral stricture as a postoperative complication.

In bivariate analyses, statistical significance is noted for age, tumor grade and tumor size with $p$-values of $0.018,0.047$ and 0.014 , respectively. In the multivariate analysis, statistical significance is noted for age and tumor size with p-values of 0.017 and 0.042 , respectively. However, non-significance is noted in the tumor grade group with a p-value of 0.286 (Table 3 ).

The incidence of UTUC in women was more than 2 fold higher than that in men, but the male-to-female hazard ratio of UTUC recurrence was 2.090 with $95 \% \mathrm{Cl}(0.704-6.201)$ (Table 4).

We treated UTUC of the renal pelvis by Flexible URS, compared with ureteral UTUC treated by rigid URS; no significance is noted between these two groups.

In both bivariate and multivariable analyses, tumor stage was not significant. Only 2 patients had Tis stage; no recurrence was found in these patients. Most patients $(n=20)$ have small tumors $(<2 \mathrm{~cm})$; after laser ablation, the recurrence rate is $25 \%$. Both bivariate and multivariable analyses achieved statistical significance. The hazard ratio of large tumors $(>2 \mathrm{~cm})$ to small tumors was 3.225 with $95 \% \mathrm{Cl}(1.041-$ 9.988).

Five patients received intra-ureteral (or intra-pelvic) chemotherapy with mitomycin or epirubicin, the recurrence rate of patients with or without intraureteral chemotherapy is not statistically significant.

We used the Kaplan-Meier estimate for survival rate analysis (Table 5). Because the mean duration of follow-up was 25 months, we estimated 2 years of local recurrence-free survival, bladder recurrence-free survival, metastasis-free survival, and cancer-specific survival. With regard to the 2 years of local recurrence-free survival, the use of the Flexible URS for laser ablation of UTUC was not inferior to the rigid URS, the p-value of the log-rank test was 0.972 .

High-grade UTUC is a higher tendency of recurrence than did a low-grade tumor and had statistical significance with a p-value of 0.0477 (Fig. 1). Biopsy stage was not significant by the log-rank test (Fig. 2). Large tumors $(>2 \mathrm{~cm})$ had a higher tendency of recurrence than did small tumors $(<2 \mathrm{~cm})$ and showed statistical significance with a p-value of 0.0066 (Fig. 3). 
We combined two of three tumor characteristics (stage, size, and grade of tumor) for subgroup analyses. In the tumor grade + tumor size group, statistical significance was noted with a $p$-value $=0.0275$. We noticed that small tumor size was still a lower recurrence event than of larger tumors despite that the analysis was combined with tumor grade (Fig. 4). In the tumor size + biopsy stage group, statistical significance was almost achieved as noted by the p-value of 0.0518 (Fig. 5). In the tumor grade + biopsy stage group, no significance was noted (Fig. 6).

\section{Discussion}

EAU guidelines verified the minimally invasive and conservative kidney-sparing approach for low-risk UTUC as an alternative treatment for RNU [6]. As EAU and NCCN guidelines suggest, URS treatment for UTUC should be performed in patients with low grade tumors; UTUC in solitary kidney, impaired renal function and bilateral UTUC was also imperatively indicated for KSS in highly selected patients $[6,13]$.

In a systematic review by Seisen et al. [9], only patients with low-grade and non-invasive UTUC had similar survival after URS management for UTUC versus RNU. However, in our study, only the tumor grade group and tumor size group achieved statistical significance. However, the biopsy stage group was not statistically significant. This difference may imply that both tumor size and tumor grade are more influential factors than biopsy stage in local recurrence-free survival. We surmise that the biopsy stage by URS is not consistent with the actual tumor stage because biopsy cannot precisely grasp the actual depth of tumor invasion. However, tumor size may be indicative of the grade of tumor invasion.

Due to the high prevalence of UTUC in southwestern Taiwan, many patients cannot fit in the low-risk group. In the review by Fiuk et al., they extended the indication for KSS to the following populations: (1) UTUC in solitary kidney, (2) renal insufficiency imposing the threat of hemodialysis if any further renal insult, (3) bilateral UTUC, (4) comorbidities enough to be life-limiting or to incur additional risk with RNU, and (5) low-risk tumors with stringent follow-up [14].

Therefore, we selected patients with imperative indications and analyzed the results after laser ablation of UTUC. In our study, female predominance is noted; it is speculated that female patients were highly exposed to arsenic steam during cooking from the boiling water [15]. However, our statistics showed that men had a higher tendency of recurrence with near statistical significance. Age was statistically significant in the multivariate analysis, but Chromecki et al. suggested that age was not an independent predictor of outcomes of UTUCs [16].

In endoscopic treatment for UTUC, multiple studies showed efficacy and safety $[9,17,18]$.

We used the Flexible URS combined with the Thulium laser system for treating renal pelvic UTUC. The statistical results showed no significant difference between the renal pelvic tumor (flexible URS) and ureteral tumor (rigid URS), and may result from advances in current technology that allows us to approach all parts of the renal collecting system. 
In the NCCN guidelines, low-grade UC of the renal pelvis treated by endoscopic resection is suggested to be followed by postsurgical intra-ureteral (intra-pelvic) chemotherapy or BCG [13]. In our study, a small number of patients $(n=5)$ received intra-ureteral (intra-pelvic) chemotherapy. The outcome of local recurrence was not statistically significant. Due to the high risk of acute pyelonephritis after intra-ureteral (intra-pelvic) chemotherapy, we terminated the therapy after administering it to a few patients. Repeat acute pyelonephritis will also induce permanent deterioration of renal function.

The recurrence rate of bilateral UTUC is lower than that of unilateral UTUC, but only 5 patients had bilateral disease; the statistical analysis also showed no significance. The tumor characteristics of these 5 patients were small tumor size and earlier tumor stage (Ta and Tis); thus, the lower rate of recurrence.

We combined two of three tumor characteristics (stage, size, and grade of tumor) for subgroup analyses. In the tumor grade + tumor size group, statistical significance was noted with a p-value $=0.0275$ (Fig. 4). We noticed that the subgroup of small tumor size (tumor $<2 \mathrm{~cm}$ with low/high grade) still had a lower local recurrence than did large tumors (tumor $>2 \mathrm{~cm}$ with low/high grade) (Fig. 4). The subgroup analysis of tumor size + biopsy stage also showed the same pattern as that small tumor size (tumor $<2 \mathrm{~cm}$ with $\mathrm{Tis} / \mathrm{Ta} / \mathrm{T} 1$ ) had a lower local recurrence than did large tumors (tumor $>2 \mathrm{~cm}$ with $\mathrm{Tis} / \mathrm{Ta} / \mathrm{T} 1$ ) (Fig. 5). However, no statistical significance was achieved in the subgroup analysis of tumor grade + biopsy stage (Fig. 6). These results imply that the factor of tumor size was more influential than tumor grade and biopsy stage in the prognosis of local recurrence.

Despite considerable experience treating UTUC by endoscopic management, risks of both understaging and undergrading remain. Up to $25 \%$ of UTUC lesions had been missed, and almost $50 \%$ of carcinoma in situ lesions were missed [19].

The limitations of our study included: (1) a small number of patients $(n=34),(2)$ short follow-up duration (mean $=25$ months), and (3) retrospective, single-center study design .

Because we excluded 34 patients due to (1) short follow-up duration (less than 6 months), (2) previous history of urinary bladder UC, and (3) concomitant diagnosis of UTUC and bladder UC at the first visit, it resulted in a small number of patients who were included in our study. Also, laser ablation is a novel technique for the management of UTUC in the recent decade and results in a short follow-up duration. We need a longer follow-up duration for an accurate survival estimate.

We shared our experience of laser ablation of UTUC to provide direction to regions or countries that have a high incidence of UTUC, such as southwestern and northeastern Taiwan, the Balkan area, and other Chinese herb-consuming regions.

\section{Conclusion}

Upper tract urothelial carcinoma is a multifocal disease with a high recurrence rate. In our experience, tumor size and tumor grade are influential recurrence factors in kidney-sparing surgery. However, biopsy 
stage did not achieve statistical significance in both the recurrence analyses and survival estimate. In the subgroup analysis, tumor size was a more influential factor than tumor grade in the prognosis of local recurrence.

\section{Abbreviations}

UTUC

Upper tract urothelial carcinomas

UC

Urothelial carcinomas

KSS

Kidney-sparing surgery

EAU

European Association of Urology

CTU

Computed tomography urography

CSS

cancer-specific survival

URS

Ureterorenoscopy

MRI

Magnetic resonance imaging

$\mathrm{Cl}$

Confidence interval

\section{Declarations}

\section{Acknowledgements}

The author wishes to acknowledge to Dr. Tseng and I-Jung Feng for guidance.

\section{Funding}

We receive no funding support.

\section{Author information:}

\section{Affiliations}

Division of Urology,Department of Surgery, Chi Mei Medical Center, Tainan City, Taiwan Yu-Che Hsieh, Steven K. Huang, Chia-Cheng Su, Jhih-Cheng Wang, Kun-Hung Shen, Chien-Liang Liu 
Department of Medical Research, Chi Mei Medical Center, Tainan City, Taiwan

I-Jung Feng

Department of Urology, Mackay Memorial Hospital, Taipei, Taiwan

Allen W. Chiu

Contributions

Yu-Che Hsieh: project development, manuscript writing

Chien-Liang Liu: project development, manuscript editing

I-Jung Feng: analysis and interpretation of the data

Steven K. Huang: data collection

Chia-Cheng Su: data collection

Jhih-Cheng Wang: data collection

Kun-Hung Shen: data collection

Allen W. Chiu: guidance

Corresponding author

Correspondence to Chien-Liang Liu

Ethics declarations

Ethics approval and consent to participate

The study was approved by the ethics committee of Chi Mei Medical Center. The need for individual consent was waived by the committee because of the retrospective nature of the study.

Consent for publication

Not applicable.

Competing interests

The authors declare that they have no competing interests.

Additional information

Publisher's Note 
Springer Nature remains neutral with regard to jurisdictional claims in published maps and institutional affiliations.

\section{Availability of data and materials}

The datasets used and/or analyzed during the current study are available from the corresponding author on reasonable request.

\section{References}

1. Siegel RL, Miller KD, Jemal A, et al. Cancer statistics, 2016. CA Cancer J Clin. 2016; 66: 7-30

2. -J. Chen, Y.-C. Chuang, S.-L. You, et al. A retrospective study on malignant neoplasms of bladder,lung and liver in blackfoot disease endemic area in Taiwan. Br. J. Cancer. 1986; 53: 399-405

3. Yang $\mathrm{MH}$, Chen $\mathrm{KK}$, Yen $\mathrm{CC}$, et al. Unusually high incidence of upper urinary tract urothelial carcinoma in Taiwan. Urology. 2002; 59: 681-7

4. Tan LB, Chen KT, Guo HR, et al. Clinical and epidemiological features of patients with genitourinary tract tumour in a blackfoot disease endemic area of Taiwan. BJU Int. 2008; 102: 48-54

5. Shen $\mathrm{CH}$, Chiou $\mathrm{HY}$, Tung MC et al. Clinical and demographic characteristics among patients with urothelial carcinomas of the upper urinary tract and bladder in Taiwan. J. Chin. Med. Assoc. 2017; 80: $563-8$

6. Rouprêt $M$, Babjuk $M$, Compérat $E$, et al.

EuropeanAssociation of Urology Guidelines on Upper Urinary Tract Urothelial Carcinoma: 2017 Update. Eur Urol. 2018; 73: 111 - 122

7. Cancer registry annual report, 2016 Taiwan. Health promotion administration ministry of health and welfare Taiwan. Dec 2018.

https://www.hpa.gov.tw/ Accessed July 10, 2019

8. Margulis V, Shariat SF, Matin SF,et al. Outcomes of radical nephroureterectomy: a series from the Upper Tract Urothelial Carcinoma Collaboration. 2009; 115: 1224-1233

9. Seisen T, Peyronnet B, Dominguez-Escrig JL, et al. Oncologic Outcomes of Kidney-sparing Surgery Versus Radical Nephrourecterectomy for Upper Tract Urothelial Carcinoma: A Systematic Review by the EAU Non-muscle Invasive BladderCancer Guidelines Panel. Eur Urol. 2016; 70: 1052-1068

10. Bagley $\mathrm{DH}$, Grasso M 3rd. Ureteroscopic laser treatment of upper urinary tract neoplasms. World J Urol. 2010;28: 143-9

11. Wen J, Ji ZG, Li HZ Treatment of upper tract ureothelial carcinoma with ureteroscopy and thulium laser. BMC Cancer. 2018 ;18: 196

12. Defidio L, De Dominicis M, Di Gianfrancesco L, et al. First collaborative experience with thulium laser ablation of localized upper urinary tract urothelial tumors retrograde intra-renal surgery. Arch Ital Urol Androl. 2011; 83: 147-53 
13. National Comprehensive Cancer Network. Bladder Cancer (Version 4.2019) https://www.nccn.org/ Accessed July 10, 2019.

14. Fiuk JV, Schwartz BF. Upper tract urothelial carcinoma: Paradigm shift towards nephron sparing management. World J Nephrol. 2016; 5: 158-65

15. Shao IH, Chang YH, Pang ST. Recent advances in upper tract urothelial carcinomas: From bench to clinics. Int J Urol. 2019; 26: 148-159

16. Chromecki TF, Ehdaie B, Novara G et al. Chronological age is not an independent predictor of clinical outcomes after radical nephroureterectomy. World J. Urol. 2011; 29: 473-80

17. Cutress ML, Stewart GD, Zakikhani P, et al Ureteroscopic and percutaneous management of upper tract urothelial carcinoma(UTUC): systematic review. BJU Int. 2012; 110: 614-28.

18. Musi G, Mistretta FA, Marenghi $C$ et al. Thulium laser treatment of upper urinary tract carcinoma: a multi-institutional analysis of surgical and oncological outcomes. J. Endourol. 2018; 32: 257-63

19. Yamany T, van Batavia J, Ahn J, et al. Ureterorenoscopy for upper tract urothelial carcinoma: how often are we missing lesions? Urology. 2015; 85: 311-5

\section{Figures}




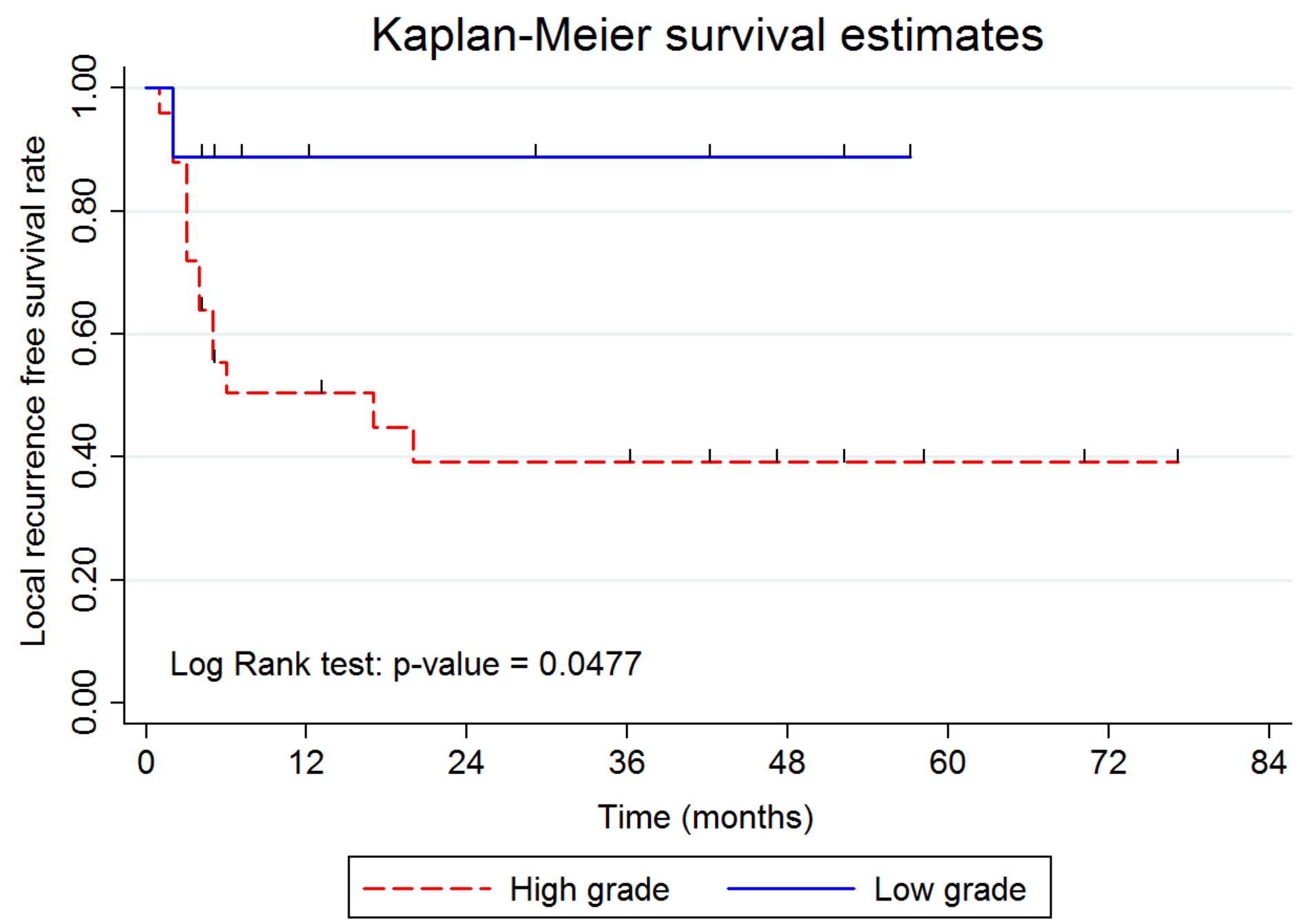

Figure 1

High-grade UTUC is a higher tendency of recurrence than did a low-grade tumor and had statistical significance with a p-value of 0.0477 . 


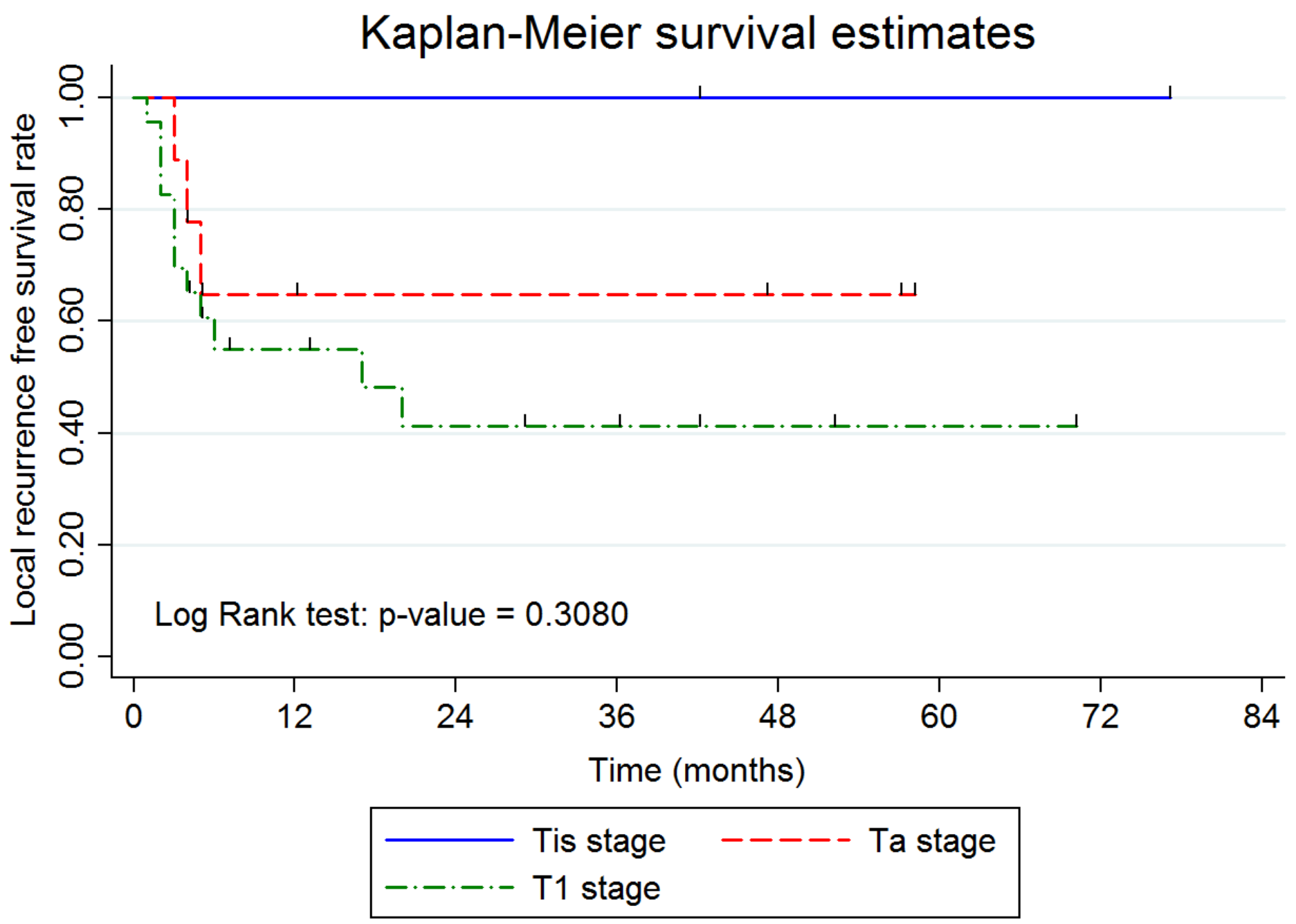

Figure 2

Biopsy stage was not significant by the log-rank test. 


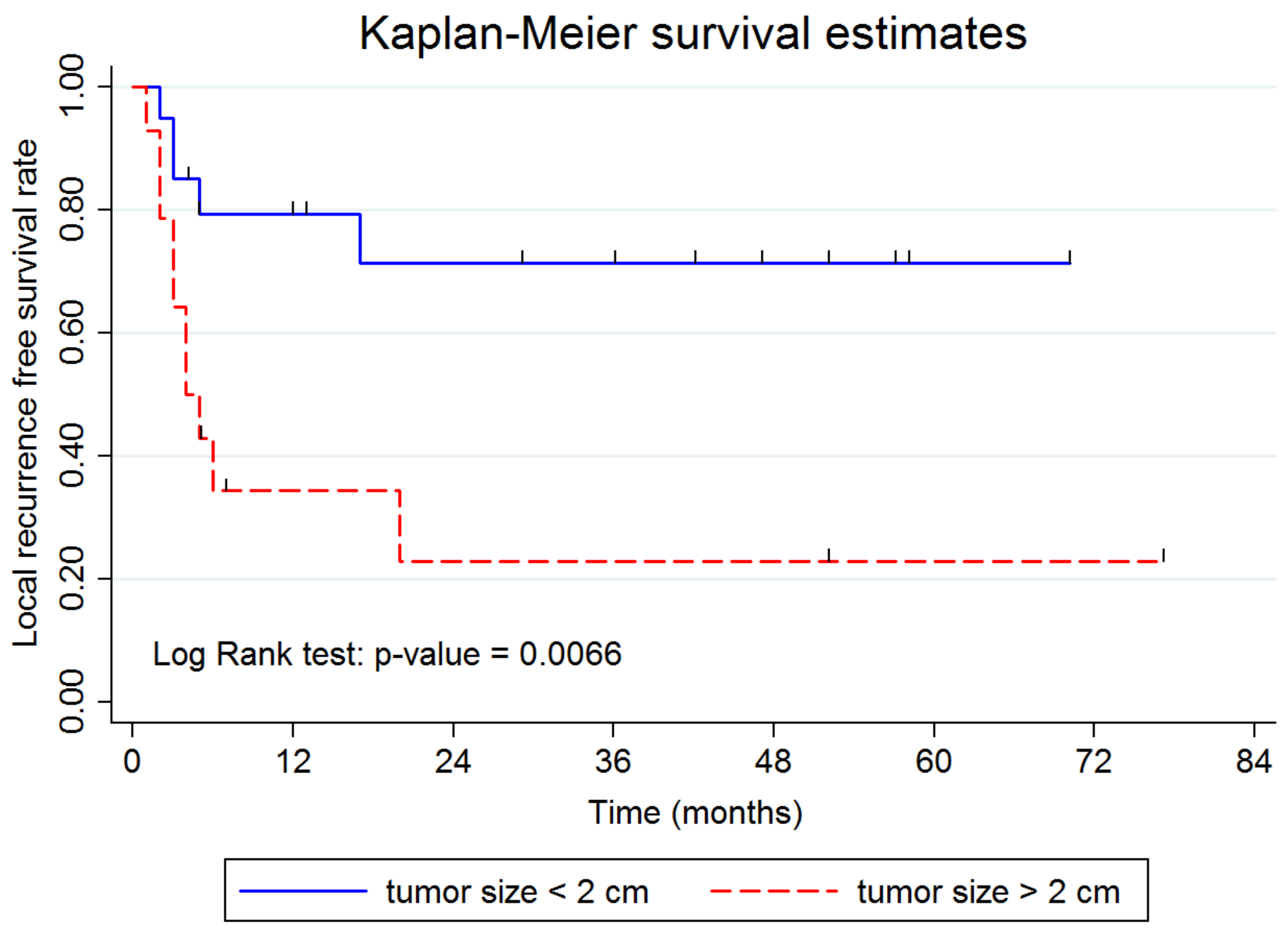

Figure 3

Large tumors $(>2 \mathrm{~cm})$ had a higher tendency of recurrence than did small tumors $(<2 \mathrm{~cm})$ and showed statistical significance with a p-value of 0.0066 . 


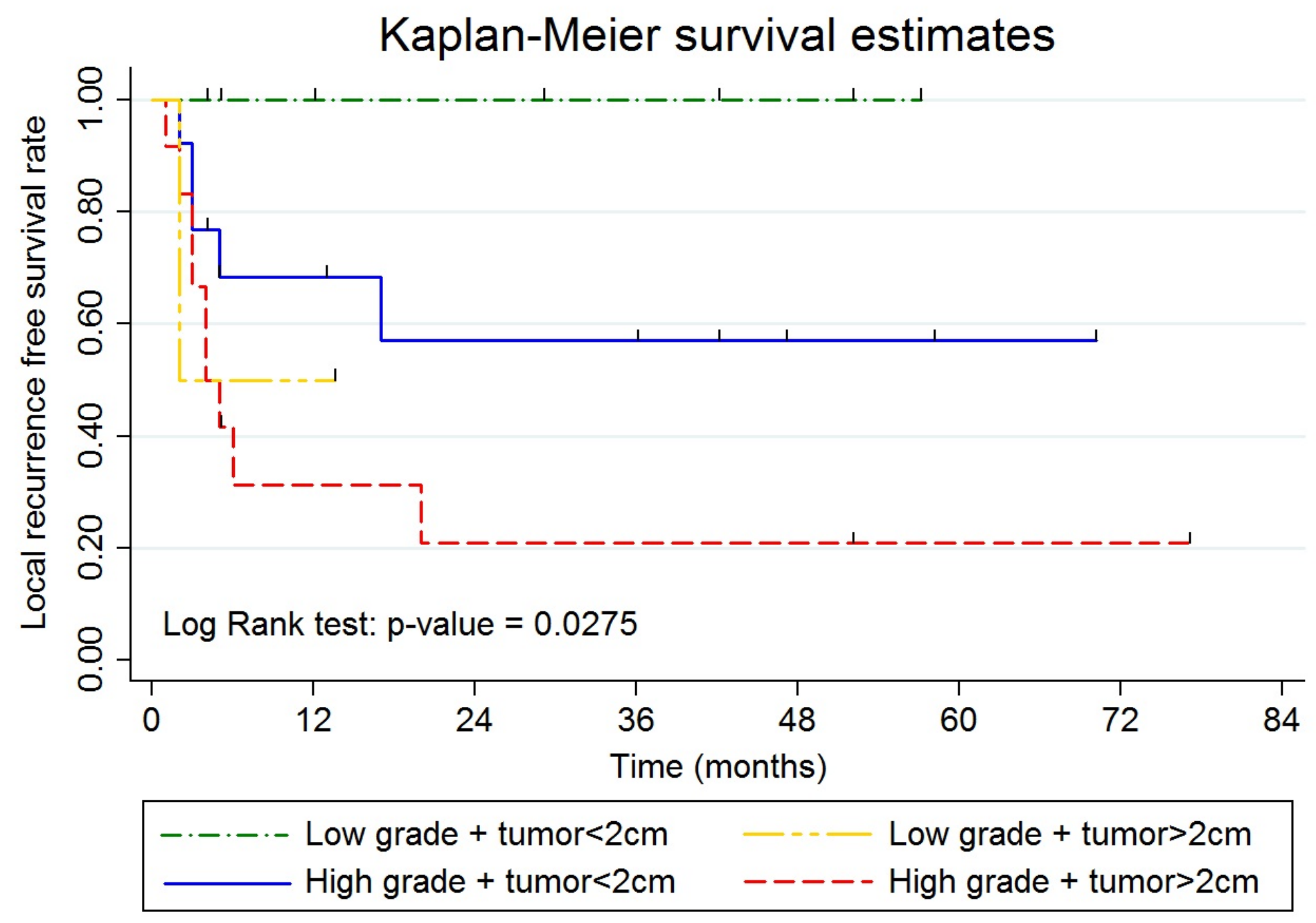

Figure 4

We noticed that small tumor size was still a lower recurrence event than of larger tumors despite that the analysis was combined with tumor grade. 


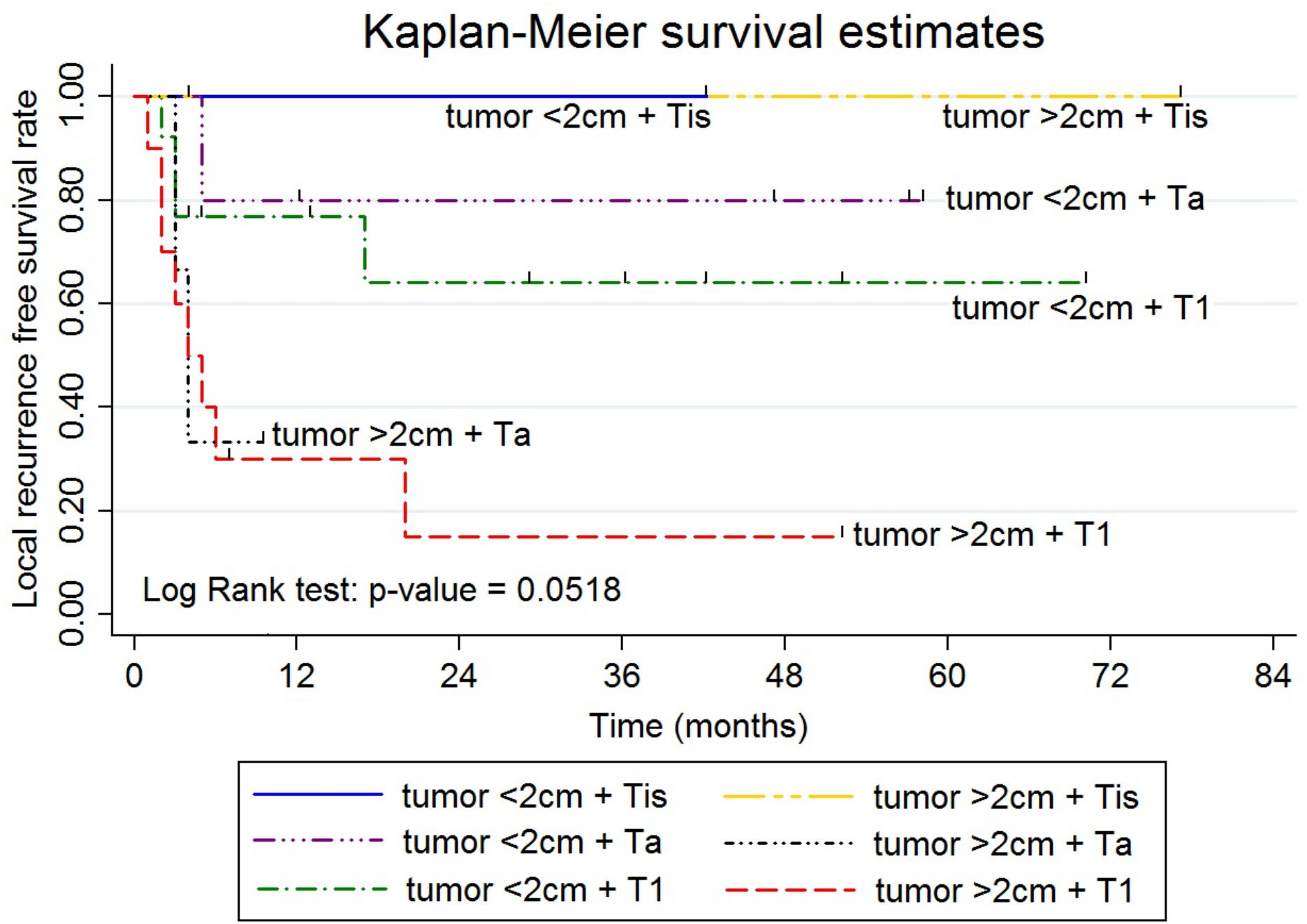

Figure 5

In the tumor size + biopsy stage group, statistical significance was almost achieved as noted by the pvalue of 0.0518 . 


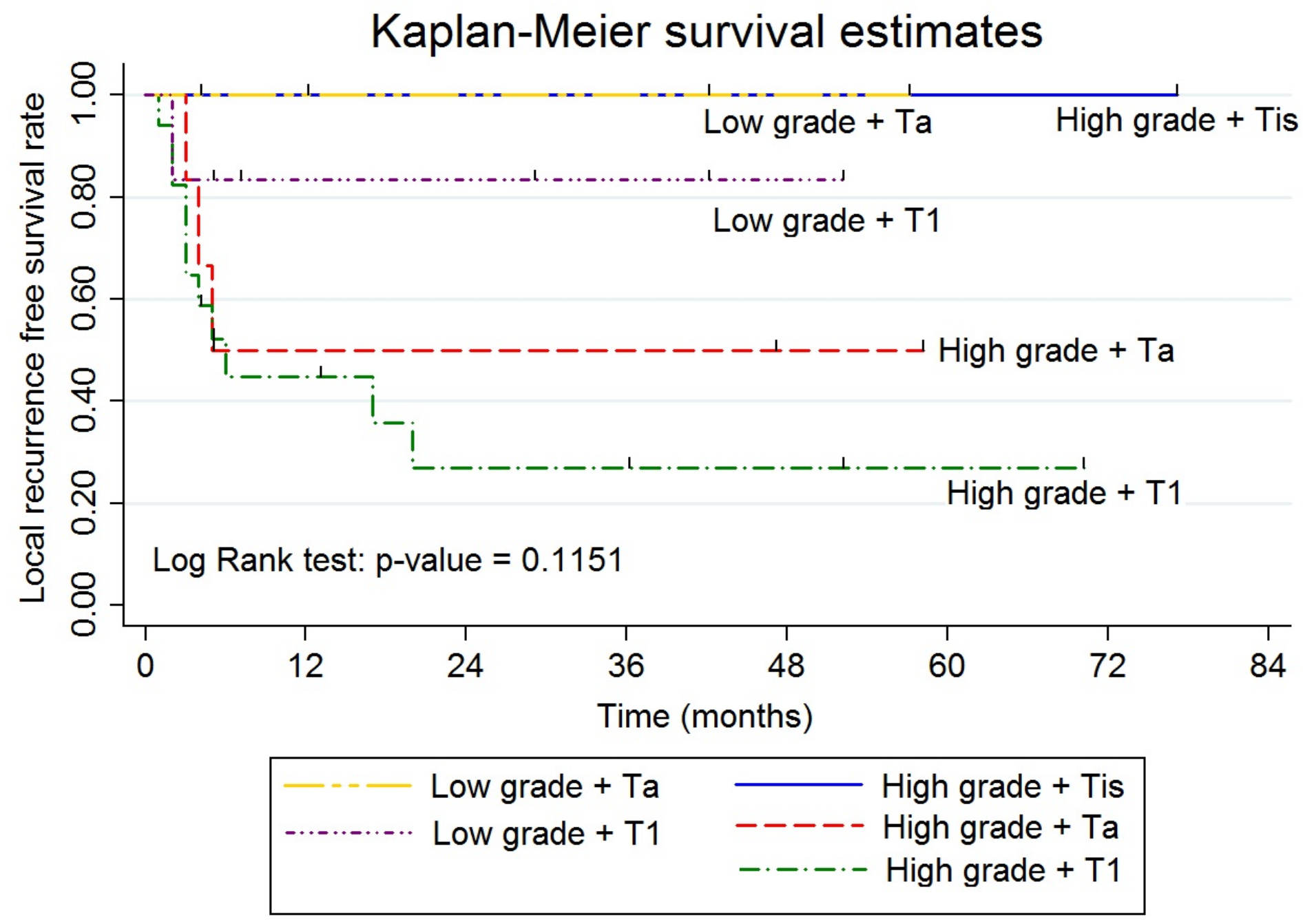

Figure 6

In the tumor grade + biopsy stage group, no significance was noted.

\section{Supplementary Files}

This is a list of supplementary files associated with this preprint. Click to download.

- FlowChart.png 